\title{
Intravenous Bevacizumab Therapy in a Patient with Hereditary Hemorrhagic Telangiectasia, ENG E137K, Alcoholic Cirrhosis, and Portal Hypertension
}

\author{
Luigi F. Bertoli ${ }^{a, b}$ Pauline L. Lee ${ }^{c} \quad$ Lauren Lallone $^{b} \quad$ James C. Barton $^{a, d, e}$ \\ a Department of Medicine, Brookwood Medical Center, Birmingham, AL, USA; \\ ${ }^{\mathrm{b}}$ Brookwood Biomedical, Birmingham, AL, USA; ${ }^{\mathrm{C}}$ Department of Molecular and \\ Experimental Medicine, The Scripps Research Institute, La Jolla, CA, USA; \\ ${ }^{\mathrm{d}}$ Southern Iron Disorders Center, Birmingham, AL, USA; ${ }^{\mathrm{e}}$ Department of Medicine, \\ University of Alabama at Birmingham, Birmingham, AL, USA
}

\section{Keywords}

Bevacizumab · ENG E137K · Hereditary hemorrhagic telangiectasia · Iron dextran ·

Transfusion · Vascular endothelial growth factor

\begin{abstract}
Intravenous bevacizumab decreased mucosal bleeding in some patients with hereditary hemorrhagic telangiectasia (HHT). We treated a 47-year-old male who had HHT, severe epistaxis, and gastrointestinal bleeding, alcoholic cirrhosis, and portal hypertension with intravenous bevacizumab $2.5 \mathrm{mg} / \mathrm{kg}$ every 2 weeks. We tabulated these measures weekly during weeks 1-33 (no bevacizumab); 34-57 (bevacizumab); and 58-97 (no bevacizumab): hemoglobin $(\mathrm{Hb})$ levels; platelet counts; units of transfused packed erythrocytes (PRBC units); and quantities of iron infused as iron dextran to support erythropoiesis. We performed univariate and multivariable analyses. We sequenced his ENG and ACVRL1 genes. Epistaxis and melena decreased markedly during bevacizumab treatment. He reported no adverse effects due to
\end{abstract}




\section{Case Reports in \\ Gastroenterology}

Case Rep Gastroenterol 2017;11:293-304

(c) 2017 The Author(s). Published by S. Karger AG, Basel www.karger.com/crg

Bertoli et al.: Intravenous Bevacizumab Therapy in a Patient with Hereditary Hemorrhagic Telangiectasia, ENG E137K, Alcoholic Cirrhosis, and Portal Hypertension

bevacizumab. Mean weekly $\mathrm{Hb}$ levels were significantly higher and mean weekly PRBC units and quantities of intravenous iron were significantly lower during bevacizumab treatment. We performed a multiple regression on weekly $\mathrm{Hb}$ levels using these independent variables: bevacizumab treatment (dichotomous); weekly platelet counts; weekly PRBC units; and weekly quantities of intravenous iron. There was 1 positive association: (bevacizumab treatment; $p=0.0046$ ) and 1 negative association (PRBC units; $p=0.0004$ ). This patient had the novel ENG mutation E137K (exon 4; c.409G $\rightarrow$ A). Intravenous bevacizumab treatment $2.5 \mathrm{mg} / \mathrm{kg}$ every 2 weeks for 24 weeks was well-tolerated by a patient with HHT due to ENG E137K and was associated with higher weekly $\mathrm{Hb}$ levels and fewer weekly PRBC units.

$$
\begin{aligned}
& \text { (C) } 2017 \text { The Author(s) } \\
& \text { Published by S. Karger AG, Basel }
\end{aligned}
$$

\section{Introduction}

Hereditary hemorrhagic telangiectasia (HHT; Osler-Weber-Rendu syndrome) is an autosomal dominant disorder characterized by telangiectases of skin and mucosae and arteriovenous malformations of the lungs, liver, and central nervous system. HHT occurs in 1 per $5,000-10,000$ persons $[1,2]$. The most common manifestation of HHT is blood loss from nasal and gastrointestinal telangiectases. Some patients develop anemia and iron deficiency [1-4]. Telangiectases and arteriovenous malformations progress with age in most patients. Penetrance of HHT phenotypes is almost $100 \%$ by the age of 40 years [1-4]. Plasma levels of vascular endothelial growth factor (VEGF) and transforming growth factor- $\beta 1$ are increased in HHT [5]. Nasal mucosal levels of VEGF, transforming growth factor- $\beta 1$, and the receptor activin receptor-like kinase 1 are also increased [6]. Mutations in genes that encode either endoglin (ENG, chromosome 9q34.1; OMIM \#13119) [7] or activin receptor-like kinase 1 (ACVRL1, chromosome 12q11-q14; OMIM \#601284) [8] account for most HHT cases.

Bevacizumab, a humanized anti-VEGF antibody, is an angiogenesis inhibitor used to treat several types of malignancies [9]. In an initial report, epistaxis and anemia due to HHT in a man with mesothelioma abated after he was treated with intravenous bevacizumab and pemetrexed [10]. Intravenous bevacizumab decreased severe nasal or sinus mucosal bleeding [11-20] or gastrointestinal bleeding $[17,19,20]$ in other patients with HHT without diagnoses of malignancy.

We report observations on a male patient with HHT, a novel ENG mutation, severe epistaxis and gastrointestinal bleeding, cirrhosis, and portal hypertension who was treated with intravenous bevacizumab for an interval of 24 weeks. We analyzed his mean weekly hemoglobin $(\mathrm{Hb})$ levels, platelet counts, units of packed erythrocytes administered by transfusion (PRBC units), and quantities of intravenous iron dextran infused to support erythropoiesis during the 24-week bevacizumab treatment interval with corresponding measures in preceding and succeeding intervals (33 and 40 weeks, respectively) without bevacizumab therapy using univariate and multivariable methods. We discuss our observations in the context of reports of bevacizumab treatment of other patients with HHT and severe mucosal bleeding. 


\section{Case Reports in Gastroenterology}

Case Rep Gastroenterol 2017;11:293-304

(c) 2017 The Author(s). Published by S. Karger AG, Basel www.karger.com/crg

Bertoli et al.: Intravenous Bevacizumab Therapy in a Patient with Hereditary Hemorrhagic Telangiectasia, ENG E137K, Alcoholic Cirrhosis, and Portal Hypertension

\section{Case Presentation}

\section{Clinical Course}

A 40-year-old white man presented with a life-long history of innumerable telangiectases of the skin and mucosae of nasal cavities and lips. At presentation, he reported having intermittent epistaxis and melena. His mother died of central nervous system hemorrhage and his brother died of pulmonary hemorrhage. Both had HHT. Physical examination confirmed the presence of many telangiectases of the lips, nasal mucosae, and finger pads and revealed that his liver was palpable $3 \mathrm{~cm}$ below the right costal margin (Table 1). He had severe anemia ( $\mathrm{Hb} 4.8 \mathrm{~g} / \mathrm{dL})$ and elevated serum activities of alanine and aspartate aminotransferases (Table 1). Endoscopy of the upper gastrointestinal tract revealed telangiectases of the gastric antrum and proximal duodenum (Fig. 1). CT and MRI scans did not detect vascular lesions in lungs, liver, brain, or other organs. The patient met each of the 4 Curaçao criteria for diagnosis of HHT [1]. Thus, these manifestations were interpreted as HHT, chronic blood loss anemia, and probable steatohepatitis.

The patient developed alcoholism and drank $\sim 750 \mathrm{~mL}$ of liquor each day. Liver biopsy at the age of 42 years revealed severe steatohepatitis and fibrosis grade 2 (Fig. 2). He subsequently developed cirrhosis with consequent portal hypertension and splenomegaly. By the age of 45 years, he had daily epistaxis and melena attributed to HHT but no apparent bleeding from esophagogastric varices. His $\mathrm{Hb}$ levels were as low as $2.8 \mathrm{~g} / \mathrm{dL}$. Treatments with estrogen, vasopressin, thalidomide, aminocaproic acid, and endoscopic laser cautery did not decrease his severe mucosal bleeding and thus we treated him with bevacizumab at the age of 47 years.

We tabulated baseline laboratory measures during weeks 1-33 (Table 1). No bevacizumab was administered during this interval. In weeks 34-57 (total 24 weeks), we infused bevacizumab, $2.5 \mathrm{mg} / \mathrm{kg}$ every 2 weeks. Soon after initiation of bevacizumab treatment, his epistaxis and melena decreased markedly. He reported having greater energy and well-being during bevacizumab treatment, although his $\mathrm{Hb}$ level was infrequently $>7.0 \mathrm{~g} / \mathrm{dL}$. A second interval of observation without bevacizumab infusion extended from weeks 58-97 (Table 1). During the 97 weeks, he received 80 units of packed erythrocytes (PRBC) and $19.7 \mathrm{~g}$ of iron as intravenous iron dextran.

At the age of 49 years, he developed acute abdominal pain and fever and was admitted to hospital. A CT scan of the abdomen revealed marked distension of the small bowel without free air and large varices (Fig. 3). Review of selected laboratory measures over the course of his entire illness demonstrated persistent blood loss anemia, progressive decrements of serum ALT and AST activities, progressive increments of alkaline phosphatase activity, and the development of hypoalbuminemia and splenomegaly (Table 1). Except blood loss anemia, these findings were interpreted as consequences of advanced cirrhosis due to alcoholism. He died of sepsis and liver failure without evidence of a perforated viscus.

\section{Treatment with Packed Erythrocytes and Intravenous Iron Dextran}

PRBC units were transfused, as indicated. Iron as iron dextran was administered intravenously in $500 \mathrm{mg}$ doses to support erythropoiesis, as indicated [21]. We tabulated quantities of iron infused weekly (mg). 
Laboratory Methods

Complete blood counts were performed using a Cell-Dyn $1800^{\circledR}$ (Abbott Laboratories, Chicago, IL, USA). Reference ranges for Hb, leukocytes, and platelets are: 12.5-16.0 g/dL, $3.5-10.5 \times 10^{3} / \mu \mathrm{L}$, and $140-440 \times 10^{3} / \mu \mathrm{L}$, respectively.

The genes ENG (NG_009551) and ACVRL1 (NG_009549) were examined by amplification and direct sequencing to detect mutations in their coding regions and splice sites. Genomic DNA was isolated using the DNeasy Blood and Tissue Kit ${ }^{\circledR}$ (Qiagen, Gaithersburg, MD, USA). DNA amplification was performed in a 50 $\mu \mathrm{L}$ reaction mixture using 20-50 ng of genomic DNA as template, PCR buffer containing $33.5 \mathrm{~mm}$ Tris $\mathrm{HCl} \mathrm{pH} \mathrm{8.8,} 3.35 \mathrm{mM} \mathrm{MgCl}_{2}, 85 \mu \mathrm{g} / \mathrm{mL}$ BSA, $8.3 \mathrm{~mm}\left(\mathrm{NH}_{4}\right)_{2} \mathrm{SO}_{4}, 0.2 \mathrm{~mm}$ dNTPs, and $150 \mathrm{ng}$ of each primer (Table 2), for 1 cycle at $96^{\circ} \mathrm{C}$ for $1 \mathrm{~min}$, and 30 cycles at $95^{\circ} \mathrm{C}$ for $1 \mathrm{~min}, 62^{\circ} \mathrm{C}$ for $30 \mathrm{~s}$, and $72^{\circ} \mathrm{C}$ for $1 \mathrm{~min}$. PCR products were purified using QIAquick PCR Purification Kits ${ }^{\circledR}$ (Qiagen, Gaithersburg, MD, USA) and sequenced with an ABI3100 Genetic Analyzer.

\section{Statistics}

The analytic dataset consisted of observations for each of 97 consecutive weeks. We compared means of weekly data in 3 intervals using Student $t$ tests (two-tailed). We performed multiple regression on weekly $\mathrm{Hb}$ using these independent variables: bevacizumab treatment (dichotomous variable); weekly platelet counts; weekly PRBC units; and weekly intravenous iron (mg). We used Excel 2000 (Microsoft Corp., Redmond, WA, USA) and GBStat (v. 8.0 2000; Dynamic Microsystems, Inc., Silver Spring, MD, USA). Values of $p<0.05$ were defined as significant.

\section{Results}

\section{Intervals with and without Bevacizumab}

Mean weekly $\mathrm{Hb}$ levels were significantly higher during bevacizumab treatment. Mean PRBC transfused and quantities of intravenous iron were significantly lower during bevacizumab treatment (Table 3).

\section{Regression on $\mathrm{Hb}$}

We used the following independent variables: bevacizumab treatment (dichotomous); weekly platelet counts; weekly PRBC units; and weekly quantities of intravenous iron. Regression on weekly $\mathrm{Hb}$ revealed 1 positive association (bevacizumab treatment; $p=0.0046$ ); and 1 negative association (PRBC units; $p=0.0004$ ). This regression explained $28.6 \%$ of the variance in $\mathrm{Hb}$ levels (ANOVA p of regression $<0.0001$ ).

ENG and ACVRL1 Sequencing

We identified a novel mutation $\mathrm{E} 137 \mathrm{~K}$ in exon 4 of the endoglin gene $(E N G$ c. $409 \mathrm{G} \rightarrow \mathrm{A})$. No ACVRL1 mutation was identified. 


\section{Case Reports in \\ Gastroenterology}

Case Rep Gastroenterol 2017;11:293-304

(c) 2017 The Author(s). Published by S. Karger AG, Basel www.karger.com/crg

Bertoli et al.: Intravenous Bevacizumab Therapy in a Patient with Hereditary Hemorrhagic Telangiectasia, ENG E137K, Alcoholic Cirrhosis, and Portal Hypertension

\section{Discussion}

Intravenous bevacizumab treatment of the present patient with HHT and severe mucosal bleeding was associated with significantly higher Hb levels, fewer units of PRBC transfusions, and lower quantities of intravenous iron in univariate comparisons. There was a significant positive association of Hb levels with bevacizumab treatment, after adjustment for other variables. PRBC units were negatively associated with bevacizumab treatment, after adjustment for other variables. Despite these favorable outcomes associated with bevacizumab treatment, he had persistent mucosal bleeding and anemia.

Objective measures of the efficacy of intravenous bevacizumab in controlling mucosal bleeding are not standardized. Hb levels and PRBC units were significant indicators in the present patient. Efficacy measures reported in other patients with HHT and mucosal bleeding include $\mathrm{Hb}$ levels $[10,19,22]$, transfusion requirements $[17,23,24]$, serum ferritin concentrations [17], and frequency or severity of epistaxis [10, 23, 25, 26].

Further studies are needed to establish optimal intravenous bevacizumab doses and treatment schedules for patients with HHT. In 1 patient, bevacizumab $2.0 \mathrm{mg} / \mathrm{kg}$ every 2 weeks was beneficial [27]. In the present case and in another patient [15], there was objective benefit of bevacizumab $2.5 \mathrm{mg} / \mathrm{kg}$ every 2 weeks. The dose of $5 \mathrm{mg} / \mathrm{kg}$ every 2 weeks was effective in other case reports $[10-13,28]$. In a prospective, noncomparative trial of intravenous bevacizumab therapy involving 25 patients with HHT, different maintenance regimens were evaluated using simulation based on transit compartments and direct inhibition pharmacokinetic-pharmacodynamic models [26]. The simulations predicted that monthly $5 \mathrm{mg} / \mathrm{kg}$ infusions of bevacizumab should control both cardiac index and epistaxis [26]. Objective benefits persisted weeks or months after bevacizumab therapy was discontinued in some patients $[11,15,19,28]$.

Adverse events have occurred in some patients with HHT treated with intravenous bevacizumab. Of 25 patients treated with bevacizumab $5 \mathrm{mg} / \mathrm{kg}$ every 2 weeks for management of severe hepatic vascular malformations and high cardiac output, 20 patients developed headache, nausea and vomiting, asthenia, diarrhea, or pain, and 2 patients developed grade 3 hypertension [29]. A woman treated with bevacizumab $5 \mathrm{mg} / \mathrm{kg}$ every 2 weeks developed bilateral pulmonary embolism and thromboses of the right atrium and right hepatic vein [30]. A man treated with bevacizumab $5 \mathrm{mg} / \mathrm{kg}$ every 2 weeks developed tachycardia with each infusion [23]. Headache, change in taste, diarrhea, dizziness, and delayed wound healing occurred in $\geq 1$ of 5 patients treated with bevacizumab $0.125 \mathrm{mg} / \mathrm{kg}$ every 4 weeks [25]. These adverse events are consistent with those observed in patients with malignancy treated with intravenous bevacizumab [9]. The development of high-titer anti-bevacizumab antibodies is rare $[9,31]$ and has not been reported in patients with HHT.

The present patient and 2 other men treated with intravenous bevacizumab [12, 15] had different pathogenic $E N G$ alleles. Although genotype/phenotype correlations differ in HHT $[2,32]$, plasma VEGF levels and VEGF tissue expression in HHT patients with ENG mutations did not differ significantly from those of HHT patients with either ACVRL1 mutations or both ENG and ACVRL1 mutations [33]. 


\section{Conclusions}

Intravenous bevacizumab treatment $2.5 \mathrm{mg} / \mathrm{kg}$ every 2 weeks for 24 weeks was welltolerated by a male patient with HHT due to ENG E137K and was associated with higher weekly $\mathrm{Hb}$ levels and fewer weekly PRBC units.

\section{Acknowledgements}

This work was supported in part by the Brookwood Biomedical and Southern Iron Disorders Center. P.L.L. is supported by NIH 5R01DK53505-12.

\section{Statement of Ethics}

This work was performed in accordance with the guidelines of the Declaration of Helsinki. This work was approved by the Institutional Review Board of Brookwood Medical Center as a study protocol entitled "To treat patients in our clinic who have bleeding from hereditary hemorrhagic telangiectasia using a monoclonal antibody that is FDA approved for treatment of certain cancers." The Institutional Review Board of Brookwood Medical Center does not assign numbers to approved protocols. The patient described herein gave written informed consent for his participation and treatment as specified in the study protocol. This patient's sister and legal next-of-kin provided written consent for the present authors to publish this work after the death of her brother.

\section{Disclosure Statement}

None of the authors has a competing interest to report.

\section{Author Contributions}

L.F.B. conceived the study, treated the patient, and tabulated data. P.L.L. performed ENG and ACVRL1 mutation analyses. L.L. tabulated data. J.C.B. treated the patient, performed statistical analyses, and drafted the manuscript. All authors edited and approved the manuscript in its final form.

\section{References}

-1 Shovlin CL, Guttmacher AE, Buscarini E, Faughnan ME, Hyland RH, Westermann CJ, Kjeldsen AD, Plauchu H: Diagnostic criteria for hereditary hemorrhagic telangiectasia (Rendu-Osler-Weber syndrome). Am J Med Genet 2000;91:66-67.

2 Sharathkumar AA, Shapiro A: Hereditary haemorrhagic telangiectasia. Haemophilia 2008;14:12691280. 
Guttmacher AE, Marchuk DA, White RI, Jr: Hereditary hemorrhagic telangiectasia. N Engl J Med 1995;333:918-924.

Peery WH: Clinical spectrum of hereditary hemorrhagic telangiectasia (Osler-Weber-Rendu disease). Am J Med 1987;82:989-997.

Sadick H, Naim R, Sadick M, Hormann K, Riedel F: Plasma level and tissue expression of angiogenic factors in patients with hereditary hemorrhagic telangiectasia. Int J Mol Med 2005;15:591-596. Sadick H, Riedel F, Naim R, Goessler U, Hormann K, Hafner M, Lux A: Patients with hereditary hemorrhagic telangiectasia have increased plasma levels of vascular endothelial growth factor and transforming growth factor-beta1 as well as high ALK1 tissue expression. Haematologica 2005;90:818828.

McDonald MT, Papenberg KA, Ghosh S, Glatfelter AA, Biesecker BB, Helmbold EA, Markel DS, Zolotor A, McKinnon WC, Vanderstoep JL: A disease locus for hereditary haemorrhagic telangiectasia maps to chromosome 9q33-34. Nat Genet 1994;6:197-204.

Johnson DW, Berg JN, Baldwin MA, Gallione CJ, Marondel I, Yoon SJ, Stenzel TT, Speer M, Pericak-Vance MA, Diamond A, Guttmacher AE, Jackson CE, Attisano L, Kucherlapati R, Porteous ME, Marchuk DA: Mutations in the activin receptor-like kinase 1 gene in hereditary haemorrhagic telangiectasia type 2. Nat Genet 1996;13:189-195.

Avastin ${ }^{\circledR}$ (bevacizumab): Full Prescribing Information. http://www.gene.com/gene/products/information/pdf/avastin-prescribing.pdf. Genentech, Inc., South San Francisco, CA, USA, 2012.

Flieger D, Hainke S, Fischbach W: Dramatic improvement in hereditary hemorrhagic telangiectasia after treatment with the vascular endothelial growth factor (VEGF) antagonist bevacizumab. Ann Hematol 2006;85:631-632.

Bose P, Holter JL, Selby GB: Bevacizumab in hereditary hemorrhagic telangiectasia. N Engl J Med 2009;360:2143-2144.

Oosting S, Nagengast W, de Vries E: More on bevacizumab in hereditary hemorrhagic telangiectasia. N Engl J Med 2009;361:931-932.

Retornaz F, Rinaldi Y, Duvoux C: More on bevacizumab in hereditary hemorrhagic telangiectasia. N Engl J Med 2009;361:931.

Amanzada A, Toppler GJ, Cameron S, Schworer H, Ramadori G: A case report of a patient with hereditary hemorrhagic telangiectasia treated successively with thalidomide and bevacizumab. Case Rep Oncol 2010;3:463-470.

Fodstad P, Dheyauldeen S, Rinde M, Bachmann-Harildstad G: Anti-VEGF with 3-week intervals is effective on anemia in a patient with severe hereditary hemorrhagic telangiectasia. Ann Hematol 2011;90:611-612.

Jamshidi N, Miller FJ, Mandel J, Evans T, Kuo MD: Individualized therapy of HHT driven by network analysis of metabolomic profiles. BMC Syst Biol 2011;5:200.

Lazaraki G, Akriviadis E, Pilpilidis I, Parisi I, Tzilves D, Tarpangos A: Low dose of bevacizumab is safe and effective in preventing bleeding episodes in hereditary hemorrhagic telangiectasia. Am J Gastroenterol 2011;106:2204-2206.

Brinkerhoff BT, Choong NW, Treisman JS, Poetker DM: Intravenous and topical intranasal bevacizumab (Avastin) in hereditary hemorrhagic telangiectasia. Am J Otolaryngol 2012;33:349-351.

Fleagle JM, Bobba RK, Kardinal CG, Freter CE: Iron deficiency anemia related to hereditary hemorrhagic telangiectasia: response to treatment with bevacizumab. Am J Med Sci 2012;343:249-251.

Lupu A, Stefanescu C, Treton X, Attar A, Corcos O, Bouhnik Y: Bevacizumab as rescue treatment for severe recurrent gastrointestinal bleeding in hereditary hemorrhagic telangiectasia. J Clin Gastroenterol 2013;47:256-257.

Barton JC, Barton EH, Bertoli LF, Gothard CH, Sherrer JS: Intravenous iron dextran therapy in patients with iron deficiency and normal renal function who failed to respond to or did not tolerate oral iron supplementation. Am J Med 2000;109:27-32.

Epperla N, Hocking W: Blessing for the bleeder: bevacizumab in hereditary hemorrhagic telangiectasia. Clin Med Res 2015;13:32-35.

Amann A, Steiner N, Gunsilius E: Bevacizumab: an option for refractory epistaxis in hereditary haemorrhagic telangiectasia. Wien Klin Wochenschr 2015;127:631-634.

Kochanowski J, Sobieszczanska M, Tubek S, Zurek M, Pawelczak J: Successful therapy with bevacizumab in a case of hereditary hemorrhagic telangiectasia. Hum Vaccin Immunother 2015;11:680-681. 


\section{Case Reports in Gastroenterology}

25 Thompson AB, Ross DA, Berard P, Figueroa-Bodine J, Livada N, Richer SL: Very low dose bevacizumab for the treatment of epistaxis in patients with hereditary hemorrhagic telangiectasia. Allergy Rhinol (Providence) 2014;5:91-95.

26 Azzopardi N, Dupuis-Girod S, Ternant D, Fargeton AE, Ginon I, Faure F, Decullier E, Roux A, Carette MF, Gilbert-Dussardier B, Hatron PY, Lacombe P, Leguy-Seguin V, Riviere S, Corre R, Bailly S, Paintaud G: Dose-response relationship of bevacizumab in hereditary hemorrhagic telangiectasia. MAbs 2015;7:630-637.

27 Wee JW, Jeon YW, Eun JY, Kim HJ, Bae SB, Lee KT: Hereditary hemorrhagic telangiectasia treated with low dose intravenous bevacizumab. Blood Res 2014;49:192-195.

28 Mitchell A, Adams LA, MacQuillan G, Tibballs J, vanden Driesen R, Delriviere L: Bevacizumab reverses need for liver transplantation in hereditary hemorrhagic telangiectasia. Liver Transpl 2008;14:210213.

29 Dupuis-Girod S, Ginon I, Saurin JC, Marion D, Guillot E, Decullier E, Roux A, Carette MF, GilbertDussardier B, Hatron PY, Lacombe P, Lorcerie B, Riviere S, Corre R, Giraud S, Bailly S, Paintaud G, Ternant D, Valette PJ, Plauchu H, Faure F: Bevacizumab in patients with hereditary hemorrhagic telangiectasia and severe hepatic vascular malformations and high cardiac output. JAMA 2012;307:948-955.

30 Maestraggi Q, Bouattour M, Toquet S, Jaussaud R, Kianmanesh R, Durand F, Servettaz A: Bevacizumab to treat cholangiopathy in hereditary hemorrhagic telangiectasia: be cautious: a case report. Medicine (Baltimore) 2015;94:e1966.

31 Forooghian F, Chew EY, Meyerle CB, Cukras C, Wong WT: Investigation of the role of neutralizing antibodies against bevacizumab as mediators of tachyphylaxis. Acta Ophthalmol 2011;89:e206-e207. Bayrak-Toydemir P, McDonald J, Markewitz B, Lewin S, Miller F, Chou LS, Gedge F, Tang W, Coon H, Mao R: Genotype-phenotype correlation in hereditary hemorrhagic telangiectasia: mutations and manifestations. Am J Med Genet A 2006;140:463-470.

33 Sadick H, Hage J, Goessler U, Bran G, Riedel F, Bugert P, Hoermann K: Does the genotype of HHT patients with mutations of the ENG and ACVRL1 gene correlate to different expression levels of the angiogenic factor VEGF? Int J Mol Med 2008;22:575-580. 


\section{Case Reports in \\ Gastroenterology}
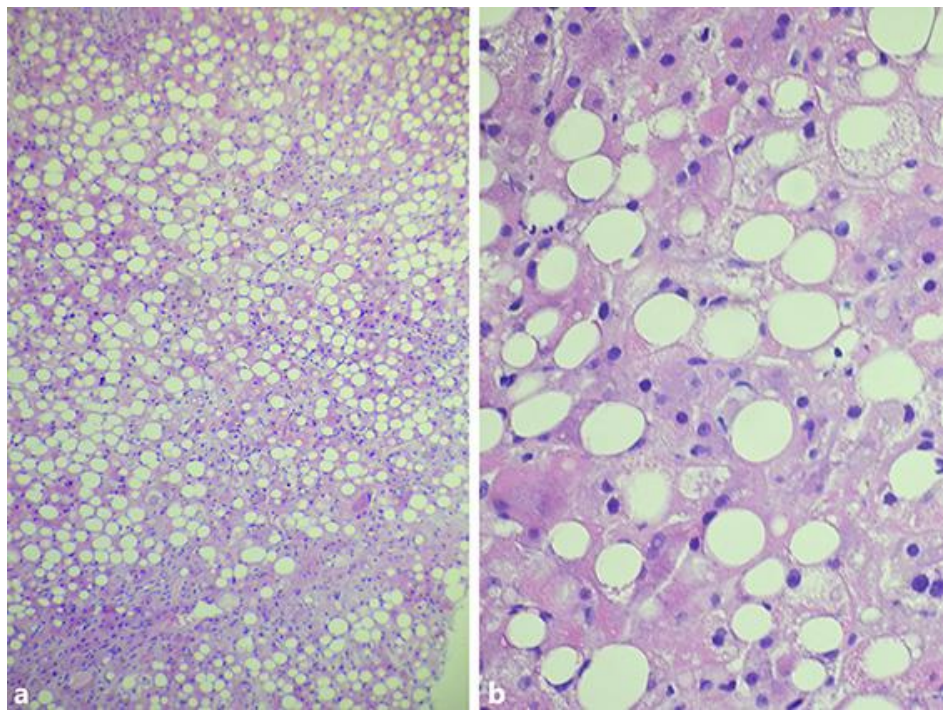

Fig. 1. Photomicrographs of the liver of a 42-year-old man with HHT and alcoholism. a Severe macrovesicular steatohepatitis (original magnification, 100×). b, Severe macrovesicular steatohepatitis (original magnification, 400x). Grade 2 fibrosis was detected with Mallory trichrome staining (not shown). Mallory bodies were not observed.

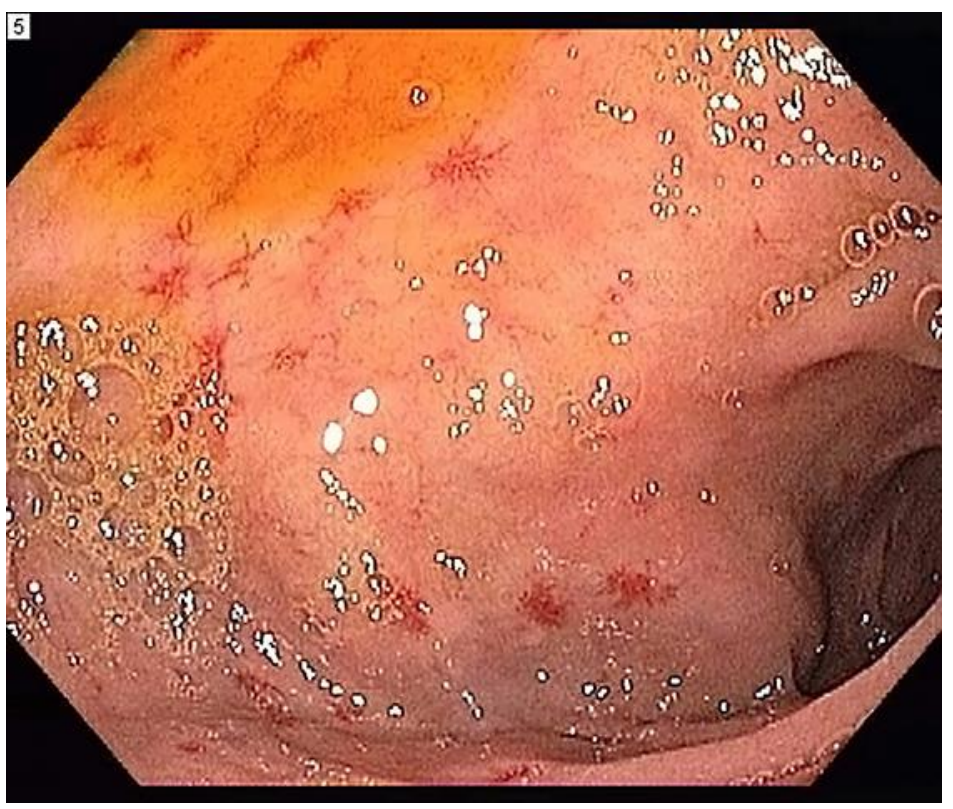

Fig. 2. Multiple spider-like mucosal telangiectases of the gastric antrum and proximal duodenum in a 40 year-old man at the diagnosis of HHT. 


\section{Case Reports in \\ Gastroenterology}

Bertoli et al.: Intravenous Bevacizumab Therapy in a Patient with Hereditary Hemorrhagic

Telangiectasia, ENG E137K, Alcoholic Cirrhosis, and Portal Hypertension

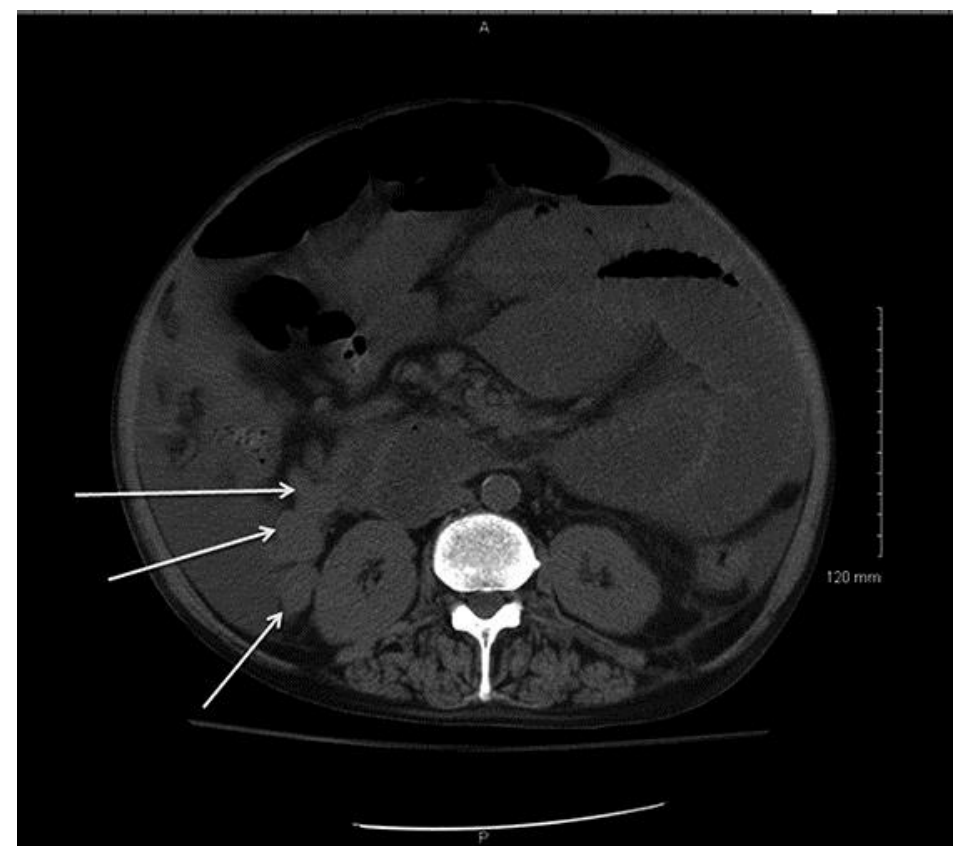

Fig. 3. Noncontrast CT scan transverse image of the abdomen in a 46-year-old man with HHT and alcoholic cirrhosis hospitalized with abdominal pain and fever. This image reveals marked distention of the small intestine, air-fluid levels in the small intestine, absence of free air in the peritoneum, and multiple large varices adjacent to the right kidney (arrows). 
Bertoli et al.: Intravenous Bevacizumab Therapy in a Patient with Hereditary Hemorrhagic Telangiectasia, ENG E137K, Alcoholic Cirrhosis, and Portal Hypertension

Table 1. Laboratory values in a man with HHT and alcoholism

\begin{tabular}{lccccc}
\hline Age, years/months & $40 / 6$ & $45 / 8$ & $46 / 2$ & $46 / 8$ & $49 / 3$ \\
Clinical events & Diagnosis & Week $1^{\mathrm{a}}$ & Week 34a & Week 58 & Final hospitalization \\
Hb, g/dL & 4.8 & 5.4 & 2.8 & 6.6 & 5.6 \\
Leukocytes, $\times 10^{3} / \mu \mathrm{L}$ & 3.0 & 2.4 & 4.4 & 4.0 & 2.6 \\
Platelets, $\times 10^{3} / \mu \mathrm{L}$ & 265 & 37 & 199 & 92 & 93 \\
Bilirubin, total, $\mathrm{mg} / \mathrm{dL}$ & 0.7 & 0.6 & 0.4 & 0.9 & 1.1 \\
Bilirubin, unconjugated, mg/dL & 0.32 & 0.28 & 0.16 & 0.48 & 0.56 \\
Albumin, g/dL & 3.1 & 2.5 & 2.6 & 3.1 & 1.6 \\
ALT, IU/L & 65 & 29 & 35 & 28 & 15 \\
AST, IU/L & 104 & 23 & 37 & 40 & 17 \\
Alkaline phosphatase, IU/L & 93 & 206 & 156 & 208 & 800 \\
Liver/spleen palpable, cm & $3 / 0$ & $6 / 0$ & - & - & $3 / 2$ \\
\hline
\end{tabular}

ALT, alanine aminotransferase; AST, aspartate aminotransferase. Reference ranges: Hb 12.0-18.0 g/dL; leukocytes $4.1-10.9 \times 10^{3} / \mu \mathrm{L}$; platelets $140-440 \times 10^{3} / \mu \mathrm{L}$; total bilirubin $0.1-1.2 \mathrm{mg} / \mathrm{dL}$; direct bilirubin 0.00-0.40 mg/dL; ALT 0-40 IU/L; AST 0-55 IU/L; and alkaline phosphatase 25-150 IU/L.

a We tabulated baseline laboratory measures for the present study during weeks $1-33$. No bevacizumab was administered during this interval. In weeks 34-57 (total 24 weeks), we infused bevacizumab, $2.5 \mathrm{mg} / \mathrm{kg}$ every 2 weeks. During weeks 58-97, no bevacizumab was administered. 


\section{Case Reports in Gastroenterology}

Table 2. Primers for $E N G$ and $A C V R L 1$ sequencing

\begin{tabular}{|c|c|c|c|}
\hline Forward primer & Sequence & Reverse primer & Sequence \\
\hline ENG Ex $1 \mathrm{~F}$ & CCCAGTGACAAAGCCCGTGGCACT & ENG Ex 1R & CAAGGATGGCTCTGCTGGGCGTGAG \\
\hline ENG Ex $2 \mathrm{~F}$ & GATATCCACCTCATAAGGTGGCTG & ENG Ex 2R & ATGCCCACATCACTCTCTTGGCAG \\
\hline ENG Ex 3F & GTGGAAGCATCCAAATCATCACTG & ENG Ex 3R & AGGACCCTGGTGAATAATGTCAAG \\
\hline ENG Ex 4F & GCTGACTCCACAAATTACTTCCTG & ENG Ex 4R & TGCCCAAGTTTGAGGTGTGGGCCAG \\
\hline ENG Ex 5F & СССTCTGCAGCACCGTCCTGCCTG & ENG Ex 5R & GAGAAAGCGACTGTGCTCTCACAG \\
\hline ENG Ex 6F & CTGTGAGAGCACAGTCGCTTTCTCCT & ENG Ex 6R & CTGCTGTGTCCCCACTCCTGCTGCG \\
\hline ENG Ex 7F & GCAGCAGGAGTGGGGACACAGCAG & ENG Ex 7R & ATCTTGGCTCACTGCAACCTCCAT \\
\hline ENG Ex 8F & GAGGTTGCAGTGAGCCAAGATCGT & ENG Ex 8R & AGGCTTGCAGAGGGACGTGACTTG \\
\hline ENG Ex 9F & GGTTGTGGTCAGTCCTTGGTGCTG & ENG Ex 9R & CTGCAGCCTGCTCTCCCAAACACA \\
\hline ENG Ex $10 \mathrm{~F}$ & TGTGTTTGGGAGAGCAGGCTGCAG & ENG Ex 10R & ACCGAGGCATTCCAGACACACATGG \\
\hline ENG Ex $11 \mathrm{~F}$ & CTCCACAGGGCCATGATGCCTGTT & ENG Ex 11R & TCTCTCCСТCTCCCGTGCACCCAG \\
\hline ENG Ex $12 \mathrm{~F}$ & TTTCCACTGTGAGGACTCAGGGGT & ENG Ex 12R & TGCCAGGCCACATGCCTGATTAAG \\
\hline ENG Ex $13 F$ & CAGAGGCATCCAGCTACGAAGCGGT & ENG Ex 13R & TGCCCAGGCCGTTTCTCAGGGCTG \\
\hline ENG Ex 14R & AGAGCTGGCACCAAAGCCCACATG & ENG Ex 14R & ACCGCCACCACGGGCTCCCGCTTG \\
\hline ACVRL1 Ex 1F & TACAGTCTCGGCTCTGTCTCCCACG & ACVRL1 Ex 1R & CAGGAGCAGCTTGCCTTTCTAATG \\
\hline ACVRL1 Ex 2F & AACTCTGTGATTTCCTCTGGGCAG & ACVRL1 Ex 2R & TTCTCCCCAGCTTCTCAAGTTCAG \\
\hline ACVRL1 Ex 3F & TCAGACGAGAGGGACAGTAGGACAG & ACVRL1 Ex 3R & CTTTATTGGCCAGAGCATGAGAGG \\
\hline ACVRL1 Ex 4F & GGACTCTGGGATCTAACTGGCAGAG & ACVRL1 Ex 4R & TGGGTCACTGCAAGCTCCTCACTCG \\
\hline ACVRL1 Ex 5F & GGAGCTTGCAGTGACCCAGCAGGT & ACVRL1 Ex 5R & CACCGCCTGTGATTCCAGTAGCCAA \\
\hline ACVRL1 Ex 6F & AACCTAAGGGTCTGGGGTTCTGTG & ACVRL1 Ex 6R & GTTCTGTTAATGTCTGGAGGTCTG \\
\hline ACVRL1 Ex 7F & CTAGCTTAGCAGTGACCCAGTCCAT & ACVRL1 Ex 7R & ATCATGGTCACCGCCCACAGGCAAAG \\
\hline ACVRL1 Ex 8F & CTCTCTGTCCCACTGTTTCTCTCAGT & ACVRL1 Ex 8R & GGCCATGGGCACTGGCCATGGCTG \\
\hline ACVRL1 Ex 9F & ATTGCATTATACTGTCCCTCTCAGG & ACVRL1 Ex 9R & GAGGCCTCAGACACAAGTTCCTGG \\
\hline ACVRL1 Ex 10F & САTCCTTTCTCTCCTGCTTATGTCT & ACVRL1 Ex 10R & CGCTTTGAGCAGGCCAGACAGCAG \\
\hline
\end{tabular}

Table 3. Observations in a man with HHT and alcoholism

\begin{tabular}{llll}
\hline Interval, weeks & $1-33$ & $34-57$ & $58-97$ \\
Bevacizumab, $2.5 \mathrm{mg} / \mathrm{kg}$ every 2 weeks & no & yes & no \\
$\mathrm{Hb}, \mathrm{g} / \mathrm{d}$ & $5.4 \pm 1.0(p=0.0101)$ & $6.5 \pm 1.7$ & $4.6 \pm 1.4(p<0.0001)$ \\
Platelets, $\times 10^{3} / \mu \mathrm{L}$ & $203 \pm 60(p=0.0454)$ & $160 \pm 65$ & $184 \pm 44(0.1685)$ \\
Packed erythrocytes, units & $2.2 \pm 1.1(p=0.0001)$ & $1.0 \pm 0.9$ & $2.3 \pm 1.5(p=0.0001)$ \\
Iron dextran, mg & $200 \pm 240(p=0.0209)$ & $60 \pm 160$ & $160 \pm 200(p=0.0300)$ \\
\hline
\end{tabular}

Variables are displayed as means of weekly values \pm 1 standard deviation. $p$ values in interval columns $1-$ 33 and 58-97 represent comparisons with observations in bevacizumab treatment interval 34-57 weeks. 